\title{
Choline supplementation improves the lipid metabolism of intrauterine-growth-restricted pigs
}

\author{
Wei Li', Bo Li ${ }^{1}$, Jiaqi Lv', Li Dong ${ }^{2}$, Lili Zhang ${ }^{1}$, and Tian Wang ${ }^{1, *}$
}

* Corresponding Author: Tian Wang Tel: +86-25-8439-6483, Fax: +86-25-8439-5314 E-mail: tianwangnjau@163.com

${ }^{1}$ College of Animal Science and Technology, Nanjing Agricultural University (NJAU), Nanjing 210095,

China

${ }^{2}$ College of Animal Science and Technology, Yangzhou University, Yangzhou 225009, China

\section{ORCID}

Wei Li

https://orcid.org/0000-0003-4247-213X Bo Li

https://orcid.org/0000-0003-0308-2155

Jiaqi Lv

https://orcid.org/0000-0002-4778-5832

Li Dong

https://orcid.org/0000-0002-8150-3544

Lili Zhang

https://orcid.org/0000-0001-9150-0833

Tian Wang

https://orcid.org/0000-0002-9038-5009

Submitted Sept 30, 2015; Revised Dec 14, 2015; Accepted May 19, 2016
Objective: The objective of this study was to investigate the effects of dietary choline supplementation on hepatic lipid metabolism and gene expression in finishing pigs with intrauterine growth retardation (IUGR).

Methods: Using a $2 \times 2$ factorial design, eight normal birth weight (NBW) and eight IUGR weaned pigs were fed either a basal diet (NBW pigs fed a basal diet, NC; IUGR pigs fed a basal diet, IC) or a diet supplemented with two times more choline than the basal diet (NBW pigs fed a high-choline diet, NH; IUGR pigs fed a high-choline diet, IH) until $200 \mathrm{~d}$ of age. Results: The results showed that the IUGR pigs had reduced body weight compared with the NBW pigs ( $p<0.05$ from birth to $d 120 ; p=0.07$ from $d 120$ to 200). Increased ( $p<0.05$ ) free fatty acid (FFA) and triglyceride levels were observed in the IUGR pigs compared with the NBW pigs. Choline supplementation decreased $(p<0.05)$ the levels of FFAs and triglycerides in the serum of the pigs. The activities of malate dehydrogenase and glucose 6-phosphate dehydrogenase were both increased $(\mathrm{p}<0.05)$ in the livers of the IUGR pigs. Choline supplementation decreased $(p<0.05)$ malate dehydrogenase activity in the liver of the pigs. Gene expression of fatty acid synthase (FAS) was higher $(\mathrm{p}<0.05)$ in the IC group than in the other groups, and choline supplementation decreased $(\mathrm{p}<0.05)$ FAS and acetyl-CoA carboxylase a expression in the livers of the IUGR pigs. The expression of carnitine palmitoyl transferase $1 \mathrm{~A}(\mathrm{CPT} 1 \mathrm{~A})$ was lower $(\mathrm{p}<0.05)$ in the IC group than in the other groups, and choline supplementation increased $(\mathrm{p}<0.05)$ the expression of CPT1A in the liver of the IUGR pigs and decreased $(p<0.01)$ the expression of hormone-sensitive lipase in both types of pigs. The gene expression of phosphatidylethanolamine $\mathrm{N}$-methyltransferase (PEMT) was higher $(\mathrm{p}<0.05)$ in the IC group than in the other groups, and choline supplementation significantly reduced $(\mathrm{p}<0.05)$ PEMT expression in the liver of the IUGR pigs.

Conclusion: In conclusion, the lipid metabolism was abnormal in IUGR pigs, but the IUGR pigs consuming twice the normal level of choline had improved circulating lipid parameters, which could be related to the decreased activity of nicotinamide adenine dinucleotide phosphate-generating enzymes or the altered expressions of lipid metabolism-related genes.

Keywords: Choline; Lipid Metabolism; Intrauterine Growth Retardation; Liver; Pig

\section{INTRODUCTION}

Intrauterine growth retardation (IUGR) is defined as a fetal weight below the 10th percentile and uterine growth below the 2.5 percentile for a given gestational age [1]. The mammalian embryo/fetus with IUGR usually shows retarded development during gestation and organ systems malfunction later in life. The naturally-occurring IUGR pig was recognized as an ideal model for the study of human IUGR [2]. Based on our previous study, newborn IUGR piglets had fatty hepatic infiltrates and cytoplasmic vacuolization in the liver [3]. Investigation of the hepatic proteome also suggested that the IUGR fetus had a lower activity of lipoprotein lipase (LPL) [4]. Abnormal lipid metabolism in the liver has proven to be closely related to 
the development of metabolic syndrome (MetS) [5], which has been widely observed in adult IUGR offspring exhibiting catchup growth [6]. Although significant metabolic abnormalities have been observed in adult IUGR rats exhibiting catch-up growth [7], very few studies have been conducted that examine the hepatic lipid metabolism of adult IUGR pigs.

As a common B vitamin in feed, choline serves as a methyl group donor and a precursor of phosphatidylcholine (PC), which is involved in very low-density lipoprotein (VLDL) assembly in the liver. Although the improvement in growth performance and the decrease in liver lipid content as a result of choline supplementation in poultry rations are well established, studies of choline in pigs are limited and the results are inconsistent [8]. The discrepancy regarding choline's effects on growth and lipid metabolism may be related to species differences, the level of choline supplementation, or the length of the experiment period. As the choline oxidase activity in pig livers is relatively lower compared with broilers [9], we speculated that choline or its metabolites might take more time to show significant effects in pigs. It has been reported that IUGR pigs have a significantly decreased serum choline content compared with normal pigs [10], suggesting that more choline in the diet might be necessary for IUGR pigs to maintain normal lipid metabolism, including PC synthesis. In this study, we investigated the effect of long-term choline supplementation on lipid metabolism and hepatic gene expression in IUGR pigs.

\section{MATERIALS AND METHODS}

\section{Animals and experimental design}

Pigs from Large White $\times$ Landrace sows mated to Landrace boars were used in this study. During the entire pregnancy period, sows were fed a gestation diet $(2 \mathrm{~kg} / \mathrm{d}$, meeting the NRC [11] recommendations for nutrient intake) and had free access to water. Piglets with a birth weight within 1 standard deviation (SD) of the mean birth weight were identified as normal birth weight (NBW), and piglets with a birth weight more than -2 SD below the mean birth weight were defined as IUGR, as previously described [1]. At the time of parturition (d 114 \pm 1 of gestation), a total of eight pairs of male piglets (eight NBW pigs: $1.51 \mathrm{~kg} \pm 0.11$; eight IUGR pigs: $0.93 \mathrm{~kg} \pm 0.10$ ) were selected from eight sows of equal parity (fourth parity) and a similar body weight (BW). One NBW pig and one IUGR pig were selected from each litter. The NBW and IUGR piglets were cross-fostered within $48 \mathrm{~h}$ after birth by two four-parity sows (eight piglets for each sow). The two sows were fed with a lactation diet that met NRC [11] requirements. Piglets were surgically castrated at $7 \mathrm{~d}$.

After weaning at $23 \mathrm{~d}$ of age, all piglets were allotted to one of four experimental treatments, which were arranged in a $2 \times 2$ factorial design consisting of intrauterine growth type (IUGR or NBW) and diet (normal or high choline) $(\mathrm{n}=4)$. The basal diet with a normal quantity of choline was formulated to meet or exceed NRC [11] nutrient requirements for post-weaning (d 23 to 73), growing (d 74 to 120), and finishing periods (d 121 to 200) (Table 1). The high-choline diet was produced from the basal diet by displacing the same quantity of corn with choline (50\% choline chloride; Shandong Enbei Group Co., Ltd, Jinan, China). The total choline content in the highcholine diet was 2 times greater than the basal diet (Table 2). The dietary choline chloride concentration was determined using the Reineckate method [12], and choline concentration was measured via chromatographyd. Pigs were reared in individual pens $(2.0 \mathrm{~m} \times 4.0 \mathrm{~m})$ equipped with one nipple drinker and a one dry feeder on fully slatted concrete floors. Pigs had free access to diets and water. During the experimental period, room temperature was controlled by ventilation fans and a heater. Room temperature, feeders, drinkers, and animal status were checked at least twice a day.

Pigs were slaughtered at $200 \mathrm{~d}$ of age after an overnight fast, by electro-stunning followed by exsanguination at a local commercial slaughterhouse. All experimental procedures used in the study were consistent with the Guide for the Care and Use of Laboratory Animals prepared by the Institutional Animal Care and Use Committee, Nanjing Agriculture University, China.

Table 1. Composition of basal diet, as-fed basis ${ }^{1)}$

\begin{tabular}{|c|c|c|c|}
\hline Item & Phase 2 & Phase 3 & Phase 4 \\
\hline \multicolumn{4}{|l|}{ Ingredient (\%) } \\
\hline Corn & 65 & 68 & 60 \\
\hline Soybean meal & 25 & 24 & 16 \\
\hline Fish meal & 2 & 0 & 0 \\
\hline Wheat bran & 4 & 4 & 4 \\
\hline Wheat grain & 0 & 0 & 16 \\
\hline L-lys $\cdot \mathrm{HCl}$ & 0.15 & 0.15 & 0.15 \\
\hline Calcium hydrogen phosphate & 0.5 & 0.5 & 0.55 \\
\hline Limestone & 0.9 & 0.9 & 0.85 \\
\hline Salt & 0.35 & 0.35 & 0.35 \\
\hline Minerals and vitamins ${ }^{2)}$ & 2.1 & 2.1 & 2.1 \\
\hline \multicolumn{4}{|l|}{ Calculated composition } \\
\hline ME (MJ/kg) & 13.47 & 13.49 & 13.49 \\
\hline $\mathrm{CP}(\%)$ & 18.7 & 17.3 & 15.3 \\
\hline Lys (\%) & 1.07 & 0.95 & 0.76 \\
\hline $\mathrm{Ca}(\%)$ & 0.61 & 0.53 & 0.52 \\
\hline $\mathrm{P}(\%)$ & 0.60 & 0.53 & 0.52 \\
\hline \multicolumn{4}{|c|}{ 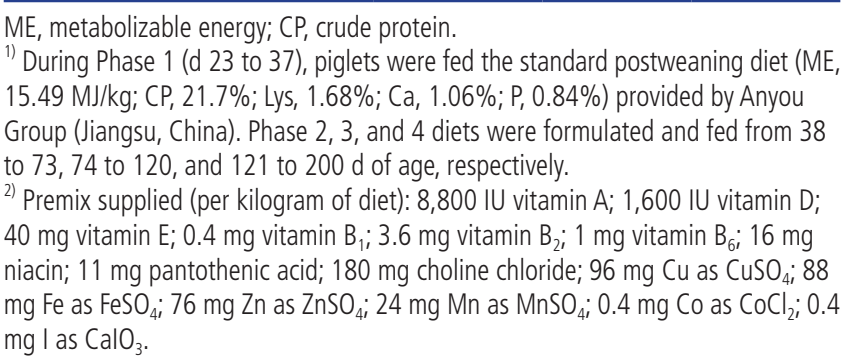 } \\
\hline
\end{tabular}


Table 2. Choline addition and dosage in diet ${ }^{1,2)}$

\begin{tabular}{|c|c|c|c|c|c|c|c|c|}
\hline \multirow{2}{*}{ Item (g/kg diet) } & \multicolumn{2}{|c|}{ Phase 1} & \multicolumn{2}{|c|}{ Phase 2} & \multicolumn{2}{|c|}{ Phase 3} & \multicolumn{2}{|c|}{ Phase 4} \\
\hline & Con & $\mathrm{HC}$ & Con & $\mathrm{HC}$ & Con & $\mathrm{HC}$ & Con & $\mathrm{HC}$ \\
\hline $50 \%$ Choline chloride addition & 0 & 3.60 & 0 & 3.23 & 0 & 3.12 & 0 & 3.03 \\
\hline \multicolumn{9}{|l|}{ Calculated level } \\
\hline Choline addition & 0 & 1.34 & 0 & 1.20 & 0 & 1.16 & 0 & 1.13 \\
\hline Total choline $e^{3)}$ & 1.34 & 2.68 & 1.20 & 2.40 & 1.16 & 2.32 & 1.13 & 2.26 \\
\hline \multicolumn{9}{|l|}{ Analyzed level } \\
\hline Choline & 1.59 & 2.98 & 1.33 & 2.77 & 1.40 & 2.71 & 1.40 & 2.75 \\
\hline Choline chloride & 0.08 & 1.73 & 0.24 & 1.56 & 0.25 & 1.50 & 0.25 & 1.45 \\
\hline
\end{tabular}

1) Phase 1, 2, 3, and 4 diets were fed from 21 to 38,38 to 73,73 to 120 , and 120 to $200 \mathrm{~d}$ of age, respectively.

2) Con, basal diet; $\mathrm{HC}$, diet supplemented with two times more choline than the basal diet.

${ }^{3)}$ The total choline content was calculated according to Feed Composition and Nutritive Values in China (22nd rev).

\section{Data and sample collection}

The BW was measured at the end of each period and the average daily gain (ADG) was calculated. At these same ages, blood samples $(5 \mathrm{~mL})$ were collected from all pigs via venipuncture after a $12 \mathrm{~h}$ overnight fast. Blood was allowed to clot at room temperature and was stored at $4^{\circ} \mathrm{C}$ for $4 \mathrm{~h}$ prior to harvesting serum via centrifugation $(1,500 \times \mathrm{g}$ for $15 \mathrm{~min}$ at $\left.4^{\circ} \mathrm{C}\right)$. Serum samples were stored at $-20^{\circ} \mathrm{C}$ for subsequent analyses.

All tissue samples were isolated and harvested within 15 min after death. Liver samples were taken from the left lateral lobe. The samples for enzyme analyses and mRNA extraction were flash-frozen in liquid nitrogen and stored at $-80^{\circ} \mathrm{C}$ until analyzed.

\section{Serum measurement}

The serum free fatty acid (FFA) was determined by the colorimetric method based on the formation of FFA-Cu soaps [13]. The alanine aminotransferase (ALT) and aspartate aminotransferase (AST) activities were determined by ReitmanFrankel methods [14]. The triglyceride concentration was estimated by glycednphosphat oxidase-phenol and 4-aminophenazone method and the total cholesterol was measured by the cholesterol oxidase coupled to phenol and 4-aminophenazone method [15]. The determination of high-density lipoprotein cholesterol (HDL-C), low-density lipoprotein cholesterol (LDL-C), LPL activity and hepatic lipase (HL) activity were carried out according to the instruction manual provided by the manufacturer. All parameters were analyzed in duplicate by colorimetry using commercial kits (Nanjing Jiancheng Bioengineering Institute, Nanjing, China).

\section{Enzyme analyses}

The liver tissues were homogenized in a buffer containing 0.25 M sucrose, $0.1 \mathrm{M}$ phosphate, $1 \mathrm{mM}$ ethylenediaminetetraacetic acid (EDTA), and $10 \mathrm{mM} \beta$-mercaptoethanol (pH 7.0). The homogenates were centrifuged at $105,000 \mathrm{~g}$ for $1 \mathrm{~h}$ at $4^{\circ} \mathrm{C}$ and the supernatants were collected and used for enzyme assays.
Spectrophotometric assays were used to determine the activity of glucose 6-phosphate dehydrogenase (G6PDH) [16], isocitrate dehydrogenase (ICDH) [17], malate dehydrogenase (MDH) [18], and malic enzyme (ME) [19]. All assays were run in a reaction buffer with a total volume of $1 \mathrm{~mL}$ in triplicate. For G6PDH, the buffer consisted of $50 \mathrm{mM}$ Tris (pH 7.6 Tris), $0.15 \mathrm{mM} \mathrm{NADP}^{+}, 20 \mathrm{mM} \mathrm{MnCl}_{2}, 1 \mathrm{mM}$ glucose-6-phosphate and $0.1 \mathrm{~mL}$ supernatant. For ICDH, the buffer consisted of $50 \mathrm{mM}$ Tris (pH 3.4 Tris), $0.15 \mathrm{mM} \mathrm{NADP}^{+}, 1.5 \mathrm{mM} \mathrm{MnCl}_{2}$, $0.34 \mathrm{mM}$ EDTA, $0.03 \%$ glutin, $1.5 \mathrm{mM} \mathrm{D}$, L- isocitrate and 0.1 $\mathrm{mL}$ supernatant. For ME, the buffer consisted of $50 \mathrm{mM}$ Tris (pH 7.4 Tris), $0.15 \mathrm{mM} \mathrm{NADP}^{+}, 1 \mathrm{mM} \mathrm{MnCl}_{2}, 3 \mathrm{mM} \mathrm{D}$, Lmalate and $0.1 \mathrm{~mL}$ supernatant. The buffer for $\mathrm{MDH}$ was obtained from the commercial kit (Nanjing Jiancheng Bioengineering Institute, China).

All assays were conducted within the range of linearity at $340 \mathrm{~nm}$ and $37^{\circ} \mathrm{C}$ with respect to the relation between enzyme activity and time, and enzyme activities were expressed on a per milligram of protein basis using bicinchoninic acid protein assay kit (Nanjing Jiancheng Bioengineering Institute, China).

\section{Total RNA extraction and quantitative real time- polymerase chain reaction}

Total mRNA was extracted from liver samples using Trizol reagent (Invitrogen, Shanghai, China), according to the manufacturer's protocols, with minor modifications. Briefly, $200 \mathrm{mg}$ of liver sample was added to $1 \mathrm{~mL}$ Trizol reagent and homogenized with a homogenizer (Pro 200, Pro Scientific Inc., Oxford, CT, USA) at full speed for 8 min (12 times for $30 \mathrm{~s}$, with a $10 \mathrm{~s}$ pause between repetitions). All RNA was treated with RNase-free DNase (Takara Biotechnology Co. Ltd., Dalian, China) to remove any trace of genomic DNA. The extracted RNA was dissolved in diethylpyrocarbonate-treated water. The purity and concentration of the total RNA was determined using a NanoDrop1000 (Thermo Scientific, Wilmington, DE, USA), and RNA integrity was verified via electrophoresis ( $1 \%$ agarose gel). The mRNA was reverse-transcribed using a 
PrimeScript reagent kit (TaKaRa Biotechnology Co., Ltd., China) following the manufacturer's instructions. The reverse transcription products (cDNA) were stored at $-20^{\circ} \mathrm{C}$ before being used as templates for quantitative real time-polymerase chain reaction (qRT-PCR). The qRT-PCR was carried out in triplicate in an ABI 7300 Real-Time PCR System (Applied Biosystems, Foster City, CA, USA) with a SYBR Premix Ex Taq Kit (TaKaRa Biotechnology Co., Ltd., China). The gene-specific primers are listed in Table 3. The oligonucleotide primers used for the qRT-PCR were designed to span the genomic introns and were synthesized commercially by Invitrogen Biotech Co., Ltd. (Shanghai, China). Thermal cycler conditions consisted of incubation at $95^{\circ} \mathrm{C}$ for $30 \mathrm{~s}$ followed by 40 cycles of $95^{\circ} \mathrm{C}$ for $5 \mathrm{~s}$, and then $60^{\circ} \mathrm{C}$ for $31 \mathrm{~s}$. The relative level of target gene expression, as determined by ABI software (Applied Biosystems, USA), was calculated using the comparative $2^{-\Delta \Delta C T}$ method for relative quantification [20]. The mRNA abundance of each target gene was normalized to $\beta$-actin as an internal control (housekeeping gene).

\section{Statistical analysis}

All data were analyzed as a mixed model with intrauterine growth type (T) of the pig (NBW or IUGR), content of choline (D) in diets (normal or high), and $\mathrm{T} \times \mathrm{D}$ as fixed effects and the pigs as random effects using the MIXED procedure. If the significance level of the $T \times D$ interaction was less than 0.05 , a one-way analysis of variance was conducted among the different groups. Pig was considered the experimental unit for all parameters $(\mathrm{n}=4)$ and all of the statistical analyses were performed using SPSS 17.0. The statistical significance was set at $\mathrm{p}<0.05$, and $0.05<\mathrm{p}<0.10$ was considered a tendency. The data are presented as least squares means with standard error of the mean.

\section{RESULTS}

\section{Growth performance}

The effects of intrauterine growth type and choline supplementation on the growth performance of pigs is presented in Table 4. The ADG was lower in the IUGR pigs during weaning ( $\mathrm{d} 0$ to 21$)(\mathrm{p}<0.05)$ compared with the NBW pigs. Although there were not significant differences in ADG after weaning between the NBW and IUGR pigs, IUGR pigs still maintained a lower BW from d 21 to 120 . However, we observed that the IUGR pigs showed the similar BW with the NBW pigs ( $\mathrm{p}=$ 0.07 ) at $\mathrm{d} 200$. This might be mostly due to the decrease of ADG from d 120 to 200 in NC group compared with the others, although not significant. There were no effects of dietary choline supplementation on BW or ADG, and no $\mathrm{T} \times \mathrm{D}$ interaction was observed.

\section{Serum metabolites}

The effects of intrauterine growth type and choline supplementation on the FFA, triglyceride and cholesterol levels of serum in the 200-day-old pigs are shown in Table 5. Increased $(p<0.05)$ FFA and triglyceride levels were observed in the IUGR

Table 3. Primer sequences used in quantitative real time-polymerase chain reaction

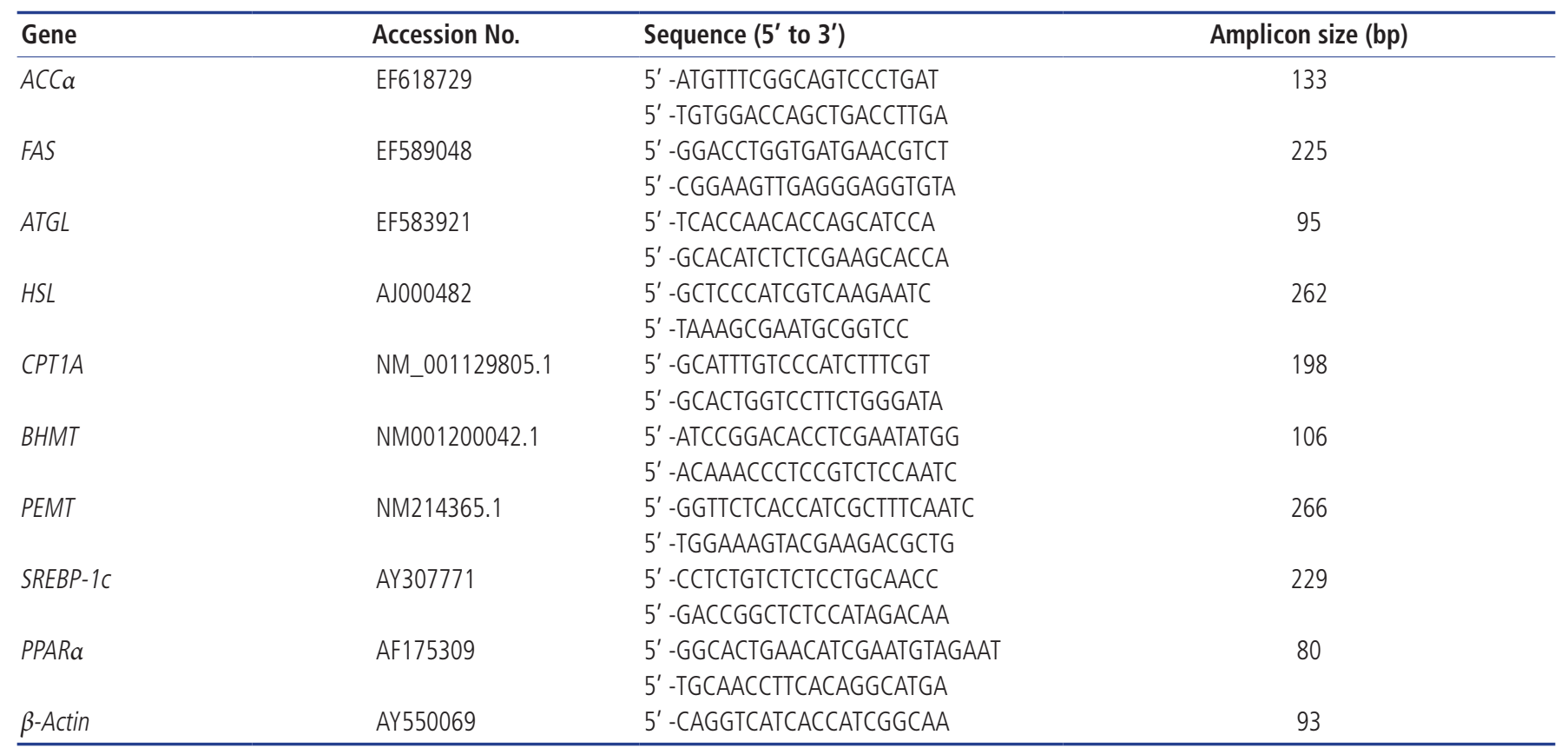

$A C C \alpha$, acetyl-CoA carboxylase $\alpha$; FAS, fatty acid synthase; ATGL, adipose triglyceride lipase; HSL, hormone-sensitive lipase; CPT1A, carnitine palmitoyl transferase 1A; BHMT, betaine-homocysteine methyltransferase; PEMT, phosphatidylethanolamine N-methyltransferase; SREBP-1C, sterol regulatory element-binding proteins $1 C$; PPAR $a$, peroxisome proliferator-activated receptor alpha. 
Table 4. Effects of intrauterine growth type and dietary choline content on growth performance for pigs

\begin{tabular}{|c|c|c|c|c|c|c|c|c|}
\hline \multirow{2}{*}{ Item } & \multicolumn{4}{|c|}{ Treatment $^{1)}$} & \multirow{2}{*}{ SEM } & \multicolumn{3}{|c|}{$p$-value } \\
\hline & NC & NH & IC & IH & & Type (T) & Diet (D) & $T \times D$ \\
\hline \multicolumn{9}{|l|}{ BW (kg) } \\
\hline $\mathrm{d} 21$ & 5.7 & 5.7 & 4.1 & 4.2 & 0.5 & $<0.01$ & - & - \\
\hline d 38 & 8.5 & 8.9 & 6.7 & 6.4 & 0.8 & 0.02 & 0.98 & 0.66 \\
\hline d 73 & 22.4 & 23.2 & 19.8 & 19.2 & 1.8 & 0.05 & 0.95 & 0.69 \\
\hline d 200 & 108.4 & 117.3 & 106.3 & 102.6 & 4.3 & 0.07 & 0.55 & 0.17 \\
\hline \multicolumn{9}{|l|}{ ADG (kg/d) } \\
\hline d 0 to 21 & 0.196 & - & 0.140 & - & 0.011 & $<0.01$ & - & - \\
\hline d 21 to 38 & 0.180 & 0.187 & 0.151 & 0.129 & 0.023 & 0.08 & 0.74 & 0.54 \\
\hline d 38 to 73 & 0.398 & 0.411 & 0.375 & 0.367 & 0.044 & 0.46 & 0.95 & 0.81 \\
\hline
\end{tabular}

SEM, standard error of the mean; BW, body weight; $A D G$, average daily gain.

1) NC, normal birth weight pigs fed basal diet; NH, normal birth weight pigs fed high-choline diet; IC, intrauterine-growth-restricted pigs fed basal diet; IH, intrauterine-growth-restricted pigs fed high-choline diet.

pigs compared with the NBW pigs. Choline supplementation decreased $(\mathrm{p}<0.05)$ the levels of FFAs and triglycerides in the serum of the pigs. There was also a $\mathrm{T} \times \mathrm{D}$ interaction $(\mathrm{p}<0.01)$ for the cholesterol level, which was significantly lower $(\mathrm{p}<0.05)$ in the $\mathrm{NH}$ group than in the other three groups. Although no significant differences in HDL-C and LDL-C were observed among treatments, the ratio of HDL-C to cholesterol was decreased $(\mathrm{p}<0.05)$ by IUGR and increased $(\mathrm{p}<0.05)$ by a high choline diet. An interaction $(\mathrm{p}<0.05)$ between pig and diet was observed in the ratio of HDL-C to cholesterol, which was increased $(p<0.05)$ with choline supplementation in NBW pigs, but not significant in IUGR pigs.

\section{Enzyme activities in the serum and the liver}

The effects of choline supplementation and a $\mathrm{T} \times \mathrm{D}$ interaction on LPL activity were both significant $(\mathrm{p}<0.05)$ (Table 6). Pigs with IUGR offered the high-choline diet had decreaed LPL activity compared with IUGR offered control diet $(\mathrm{p}<0.05)$, but there was no effect of choline supplementation on LPL activity in NBW pigs. The total activity of LPL and HL tended to be reduced $(p=0.09)$ in the choline-supplemented treatments. The activities of MDH and G6PDH were both increased $(p<0.05)$ in the livers of the IUGR pigs, and choline supplementation decreased $(p<0.05) \mathrm{MDH}$ activity (Table 7).

\section{Enzyme and transcriptional factor mRNA expression}

The relative mRNA expression of genes related to lipogenesis and lipolysis, as well as transcriptional factors in liver, are shown in Table 8. Compared with the NBW pigs, IUGR pigs had decreased expression of adipose triacylglycerol lipase (ATGL) $(\mathrm{p}<0.01)$ and increased mRNA expression of fatty acid synthase (FAS) $(\mathrm{p}<0.01)$ and phosphatidylethanolamine $\mathrm{N}$-methyltransferase (PEMT) $(\mathrm{p}<0.05)$ in the liver. The FAS, acetyl-CoA carboxylase a (ACCa), hormone sensitive lipase (HSL), and PEMT mRNA were expressed at a reduced rate $(\mathrm{p}<0.05)$ with choline supplementation. There were $\mathrm{T} \times \mathrm{D}$ interactions $(\mathrm{p}<0.05)$ for FAS, ATGL, carnitine palmitoyl transferase 1A (CPT1A), and PEMT expressions. For FAS

Table 5. Effects of intrauterine growth type and choline supplementation on the biochemical parameters of serum in the pigs

\begin{tabular}{|c|c|c|c|c|c|c|c|c|}
\hline \multirow{2}{*}{ Item } & \multicolumn{4}{|c|}{ Treatment $^{1)}$} & \multirow{2}{*}{ SEM } & \multicolumn{3}{|c|}{$p$-value } \\
\hline & NC & $\mathrm{NH}$ & IC & $\mathrm{IH}$ & & Type (T) & Diet (D) & $T \times D$ \\
\hline $\mathrm{FFA}(\mu \mathrm{Eq} / \mathrm{L})$ & 202.29 & 97.42 & 306.59 & 180.52 & 28.54 & 0.01 & $<0.01$ & 0.72 \\
\hline Triglyceride (mM) & 0.35 & 0.15 & 0.56 & 0.37 & 0.08 & 0.02 & 0.04 & 0.97 \\
\hline Cholesterol (mM) & $1.86^{\mathrm{a}}$ & $1.00^{b}$ & $1.79^{\mathrm{a}}$ & $1.83 a$ & 0.10 & $<0.01$ & $<0.01$ & $<0.01$ \\
\hline $\mathrm{HDL}-\mathrm{C}(\mathrm{mM})$ & 0.31 & 0.34 & 0.27 & 0.28 & 0.05 & 0.31 & 0.59 & 0.84 \\
\hline LDL-C (mM) & 0.98 & 0.98 & 0.93 & 1.11 & 0.10 & 0.69 & 0.38 & 0.38 \\
\hline HDL-C/Cholesterol & $0.16^{b}$ & $0.32^{\mathrm{a}}$ & $0.12^{b}$ & $0.15 b$ & 0.02 & $<0.01$ & $<0.01$ & $<0.01$ \\
\hline
\end{tabular}

SEM, standard error of the mean; FFA, free fatty acid; HDL-C, high density lipoprotein cholesterol; LDL-C, low density lipoprotein cholesterol.

1) NC, normal birth weight pigs fed basal diet; NH, normal birth weight pigs fed high-choline diet; IC, intrauterine-growth-restricted pigs fed basal diet; IH, intrauterine-growth-restricted pigs fed high-choline diet.

$a, b$ Mean values within a row with different superscripts a or $b$ are with significantly different $(p<0.05)$. 
Table 6. Effects of intrauterine growth type and choline supplementation on the activities of enzymes in the serum of the pigs

\begin{tabular}{|c|c|c|c|c|c|c|c|c|}
\hline \multirow{2}{*}{ Item } & \multicolumn{4}{|c|}{ Treatment $^{1)}$} & \multirow{2}{*}{ SEM } & \multicolumn{3}{|c|}{$\mathrm{p}$-value } \\
\hline & NC & NH & IC & $\mathrm{IH}$ & & Type (T) & Diet (D) & $T \times D$ \\
\hline LPL (U/mL) & $0.39^{b}$ & $0.36^{b}$ & $0.49^{a}$ & $0.21^{b}$ & 0.04 & 0.56 & $<0.01$ & $<0.01$ \\
\hline $\mathrm{HL}(\mathrm{U} / \mathrm{mL})$ & 0.45 & 0.41 & 0.48 & 0.44 & 0.04 & 0.52 & 0.42 & 0.98 \\
\hline $\mathrm{LPL}+\mathrm{HL}(\mathrm{U} / \mathrm{mL})$ & 0.84 & 0.76 & 0.85 & 0.59 & 0.09 & 0.37 & 0.09 & 0.34 \\
\hline $\operatorname{ALT}(\mathrm{U} / \mathrm{L})$ & 21.98 & 18.36 & 21.35 & 20.47 & 2.61 & 0.78 & 0.40 & 0.61 \\
\hline AST (U/L) & 34.54 & 26.73 & 41.75 & 38.00 & 6.39 & 0.21 & 0.41 & 0.76 \\
\hline
\end{tabular}

SEM, standard error of the mean; LPL, lipoprotein lipase; HL, hepatic lipase; ALT, alanine aminotransferase; AST, aspartate aminotransferase.

1) NC, normal birth weight pigs fed basal diet; NH, normal birth weight pigs fed high-choline diet; IC, intrauterine-growth-restricted pigs fed basal diet; IH, intrauterine-growth-restricted pigs fed high-choline diet.

$a, b$ Mean values within a row with different superscripts a or $b$ are with significantly different $(p<0.05)$.

Table 7. Effects of intrauterine growth type and choline supplementation on the activities of enzymes in the liver of the pigs

\begin{tabular}{|c|c|c|c|c|c|c|c|c|}
\hline \multirow{2}{*}{$\begin{array}{l}\text { Item } \\
\text { (U/mg prot) }\end{array}$} & \multicolumn{4}{|c|}{ Treatment $^{1)}$} & \multirow{2}{*}{ SEM } & \multicolumn{3}{|c|}{$p$-value } \\
\hline & NC & $\mathrm{NH}$ & IC & IH & & Type (T) & Diet (D) & $T \times D$ \\
\hline $\mathrm{MDH}$ & 0.47 & 0.38 & 0.86 & 0.52 & 0.03 & 0.01 & 0.02 & 0.12 \\
\hline $\mathrm{ICDH}$ & 74.19 & 66.02 & 66.28 & 60.04 & 4.23 & 0.43 & 0.41 & 0.91 \\
\hline G6PDH & 39.77 & 43.54 & 46.50 & 59.42 & 2.05 & 0.02 & 0.08 & 0.30 \\
\hline
\end{tabular}

SEM, standard error of the mean; MDH, malate dehydrogenase; ME, malic enzyme; ICDH, isocitrate dehydrogenase; G6PDH, glucose 6-phosphate dehydrogenase.

1) NC, normal birth weight pigs fed basal diet; NH, normal birth weight pigs fed high-choline diet; IC, intrauterine-growth-restricted pigs fed basal diet; IH, intrauterine-growth-restricted pigs fed high-choline diet.

and PEMT, the results showed that choline supplementation decreased FAS and PEMT mRNA expressions more dramatically $(\mathrm{p}<0.05)$ in IUGR pigs than NBW pigs. The T $\times \mathrm{D}$ interaction for CPT1A mRNA expression indicated that choline supplementation increased CPT1A mRNA expression in IUGR pigs $(\mathrm{p}<0.05)$, but did not affect the expression in NBW pigs. The expression of ATGL mRNA was increased $(\mathrm{p}<0.05)$ by choline in NBW pigs, but not in IUGR pigs.

\section{DISCUSSION}

Choline, as an essential vitamin additive in animal feed mixtures, plays a critical role in cell membrane integrity, lipid metabolism and methylation [21]. The goal of this study was to assess the effects of long-term supplementation of choline on circulating lipid parameters and hepatic lipid metabolism in IUGR pigs. We showed that IUGR pigs demonstrated catchup growth at $\mathrm{d} 200$ accompanied by abnormal lipid metabolism,

Table 8. Effects of intrauterine growth type and choline supplementation on the expression of the lipid metabolism related genes in the pigs

\begin{tabular}{|c|c|c|c|c|c|c|c|c|}
\hline \multirow{2}{*}{ Item ${ }^{1)}$} & \multicolumn{4}{|c|}{ Treatment $^{2)}$} & \multirow{2}{*}{ SEM } & \multicolumn{3}{|c|}{$\mathrm{p}$-value } \\
\hline & NC & $\mathrm{NH}$ & IC & IH & & Type (T) & Diet (D) & $T \times D$ \\
\hline $\mathrm{ACC} a$ & 1.09 & 0.66 & 0.94 & 0.19 & 0.22 & 0.19 & 0.02 & 0.49 \\
\hline FAS & $1.25^{b}$ & $1.02^{b}$ & $7.23^{\mathrm{a}}$ & $1.01^{b}$ & 0.65 & $<0.01$ & $<0.01$ & $<0.01$ \\
\hline ATGL & $1.03^{b}$ & $1.90^{\mathrm{a}}$ & $0.70^{b}$ & $0.61^{b}$ & 0.19 & $<0.01$ & 0.06 & 0.02 \\
\hline HSL & 1.14 & 0.20 & 1.45 & 0.26 & 0.28 & 0.52 & $<0.01$ & 0.67 \\
\hline CPT1A & $1.07^{b}$ & $0.90^{b}$ & $0.52^{\mathrm{a}}$ & $1.24^{b}$ & 0.17 & 0.58 & 0.15 & 0.03 \\
\hline BHMT & 1.03 & 0.73 & 0.83 & 0.70 & 0.15 & 0.46 & 0.17 & 0.60 \\
\hline PEMT & $1.02^{b}$ & $0.94^{b}$ & $2.16^{\mathrm{a}}$ & $1.27^{b}$ & 0.16 & $<0.01$ & 0.01 & 0.03 \\
\hline SREBP-1C & 1.09 & 1.43 & 2.22 & 1.24 & 0.46 & 0.33 & 0.50 & 0.18 \\
\hline PPARa & 1.08 & 0.77 & 0.53 & 0.59 & 0.18 & 0.07 & 0.49 & 0.32 \\
\hline
\end{tabular}

SEM, standard error of the mean; ACC $\alpha$, acetyl-CoA carboxylase $\alpha$; FAS, fatty acid synthase; ATGL, adipose triglyceride lipase; HSL, hormone-sensitive lipase; CPT1A, carnitine palmitoyl transferase 1A; BHMT, betaine-homocysteine methyltransferase; PEMT, phosphatidylethanolamine N-methyltransferase; SREBP-1c, sterol regulatory element-binding proteins 1C; PPARa, peroxisome proliferator-activated receptor alpha.

1) Relative mRNA levels were showed as $2^{-\Delta \Delta C T}$ values normalized to $\beta$-actin (arbitary units).

${ }^{2)} \mathrm{NC}$, normal birth weight pigs fed basal diet; NH, normal birth weight pigs fed high-choline diet; IC, intrauterine-growth-restricted pigs fed basal diet; IH, intrauterine-growth-restricted pigs fed high-choline diet.

${ }^{a, b}$ Mean values within a row with different superscripts a or $b$ are with significantly different $(p<0.05)$. 
and that choline supplementation improved lipid metabolism by decreasing circulating levels of FFAs and triglycerides, as well as LPL activity. Significantly, choline also improved hepatic lipid metabolism by decreasing nicotinamide adenine dinucleotide phosphate (NADPH) generation, down-regulating the expression of lipogenic enzymes and improving fatty acid oxidation, as well as enhancing the export of triacylglycerol from the liver. To our knowledge, this study is the first to show that a diet rich in choline has a role in regulating lipid metabolism in IUGR pigs. These findings provide novel insights into the role of choline in the lipid metabolism of IUGR offspring and provides specific evidence that choline plays different roles in IUGR and NBW pigs.

In the present study, the BW of IUGR pigs remained lower than NBW pigs prior to $d 200$, but a similar final BW (d 200) was observed for NBW and IUGR pigs. The reduced BW and growth rate in IUGR offspring, particularly in the early stages of life, has been well documented [22]. However, in the case of postnatal exposure to abundant nutrition, IUGR offspring have an opportunity for catch-up growth. A previous study also reported that pigs with low birth weight had a greater weight gain than their heavy littermates at $\mathrm{d} 105$ when crossfostered to minimize sucking competition and given free access to diets after weaning [23]. In the current study, all pigs were fed ad libitum, and the ADG data showed that catch-up growth began as early as weaning in the IUGR pigs. In addition, as we have found no reports on the effect of high choline on growth performance in pigs, the differences in ADG between NC and $\mathrm{NH}$ treatments from d 120 to 200 (although not significant) should be confirmed in the further studies with more experimental animals.

Although it seems beneficial to productive performance, catch-up growth in both IUGR animals and humans is considered an important component of MetS programming [24]. It is well accepted that MetS is generally characterized by blood lipid disorders including high FFA, triglyceride, low HDL-C and high LDL-C levels [25]. Cholesterol homeostasis is an important component of lipid metabolism. HDL-C particles promote vascular health by extracting cholesterol from the tissues (including atherosclerotic plaques) and delivering it back to the liver. Conversely, LDL-C is the classic antagonist of the circulatory system due to its propensity to bind to connective tissue in the intimal sub-layer of the arteries. Thus, increased total cholesterol (particularly LDL-C) and a reduced level of HDL-C are risk factors in the pathogenesis of coronary heart disease and metabolic diseases. In our study, we found that circulating FFA, triglyceride and cholesterol levels were increased and the HDL-C/total cholesterol ratio was decreased in IUGR pigs compared with control pigs, which might indicate a programmed disorder of lipid metabolism in IUGR pigs at $\mathrm{d} 200$.

Choline serves as a structural constituent of membrane phospholipids (PC, choline plasmalogen, and sphingomyelin) and also plays an important role in the other biological actions (cholinergic neurotransmission, platelet activating-factor formation, hepatic secretion of VLDL, and methyl transport). In humans, the beneficial effects of the Mediterranean diet in the prevention of cardiovascular disease were recently associated with a higher intake of choline [26] and subjects with a higher choline intake had a higher HDL-C level [27]. In the present study, we have also shown that high supplementation of choline has a role in increasing the circulating HDL-C/total cholesterol ratio and decreasing the total cholesterol level in the plasma of NBW pigs, but not in IUGR pigs.

LPL is a critical enzyme involved in the hydrolysis of triglycerides carried by chylomicron and VLDL [28], a process which generates FFA for energy metabolism and storage. We observed that choline supplementation decreased circulating LPL activity in IUGR pigs, which might explain the reduced levels of circulating FFAs and triglycerides. The decreased FFA and triglyceride levels in serum suggest an improved lipid metabolism status in the liver, as increased circulating FFAs and triglycerides are important component of fatty liver, liver insulin resistance and type II diabetes [29].

With the exception of FFA and triglyceride uptake, the hepatic lipid metabolism is primarily involved in the de novo synthesis and oxidation of fatty acids, as well as lipoprotein synthesis and export (Figure 1). In brief, de novo lipogenesis in the liver begins with the carboxylation of acetyl-CoA to malonyl-CoA through the actions of ACCa. FAS then converts malonyl-CoA to its primary product, palmitic acid. The $\mathrm{NADPH}$-generating enzymes, such as $\mathrm{ME}, \mathrm{MDH}, \mathrm{ICDH}$, and $\mathrm{G} 6 \mathrm{PDH}$, provide the primary sources for lipogenesis. CPT1A controls the transport of long-chain acyl-CoA into the mitochondria, which is the rate-limiting step of mitochondrial fatty acid $\beta$-oxidation in the liver. Recent studies have found that the first step in the oxidation of fatty acids is the mobilization of triacylglycerol, which is catalyzed by ATGL and HSL [30]. Although normally presenting at very low levels in the liver, ATGL and HSL both appear to channel the liberated fatty acids towards oxidation [31]. In the present study, we observed that the mRNA expression of FAS, and the activities of $\mathrm{MDH}$ and G6PDH in the liver were increased, and ATGL expression was decreased by IUGR. With a normal dietary choline content, the expression of CPT1A was also decreased in IUGR pigs compared with NBW pigs in this study, which is consistent with the existing literature on rats [32]. Because of these findings, we speculate that for IUGR pigs, there was abundant $\mathrm{NADPH}$ and more efficient enzymes for the de novo lipogenesis of fatty acids, but that the oxidation of fatty acids might be decreased, causing the accumulation of lipid droplets in the hepatocytes. The current study also shows that choline supplementation down-regulated hepatic MDH activity and mRNA expression of FAS and ACCa, but its effect of up-regu- 


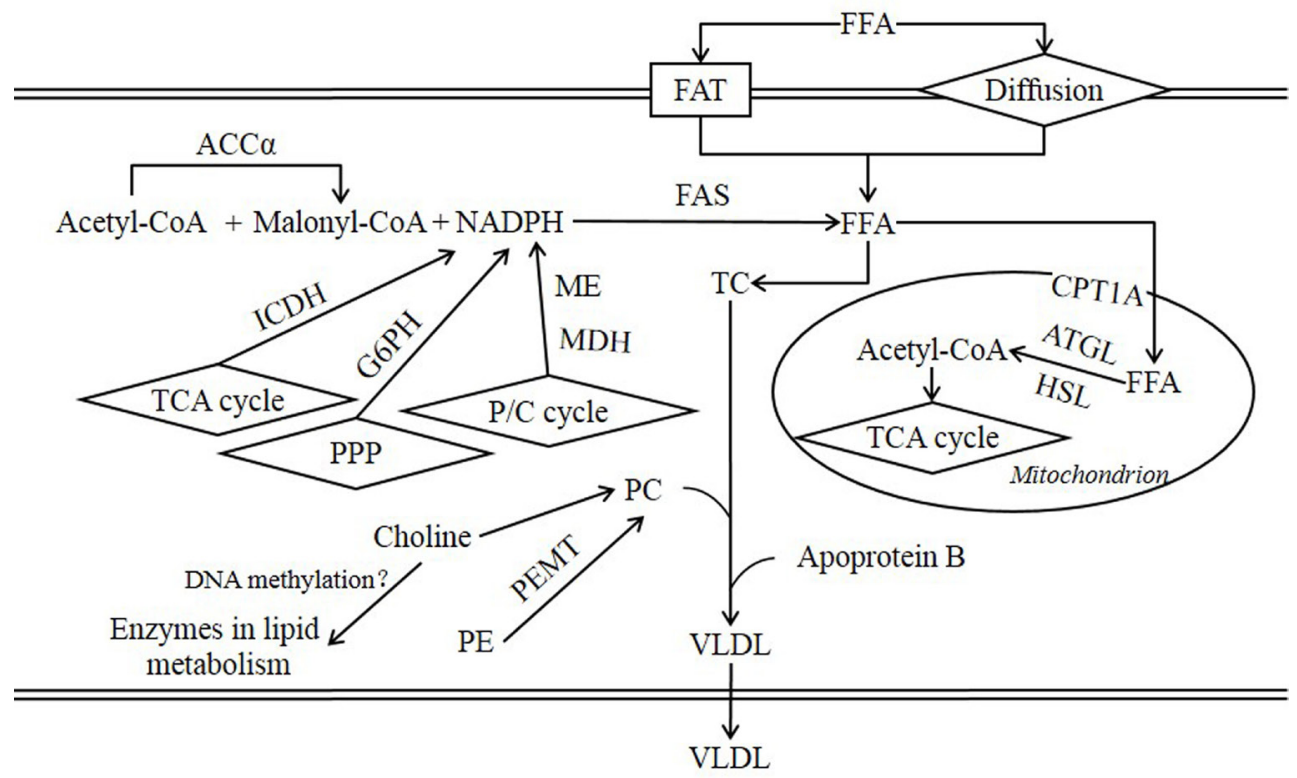

Figure 1. Effects of choline in lipid metabolism pathway. FFA, free fatty acid; FAT, fatty acid translocase; ACC $\alpha$, acetyl-CoA carboxylase $\alpha$; FAS, fatty acid synthase; ICDH, isocitrate dehydrogenase; G6PDH, glucose 6-phosphate dehydrogenase; MDH, malate dehydrogenase; ME, malic enzyme; TC, triglyceride; CPT1A, carnitine palmitoyl transferase 1A; ATGL, adipose triglyceride lipase; HSL, hormone-sensitive lipase; TCA, tricarboxylic acid cycle; PPP, pentose phosphate pathway; P/C, pyruvate/citrate; PC, phosphatidylcholine; PE, phosphatidylethanolamine; PEMT, phosphatidylethanolamine N-methyltransferase; VLDL, low-density lipoprotein.

lating hepatic CPT1A mRNA expression was only observed in IUGR pigs and not in NBW pigs. The increased expression of CPT1A is consistent with previous studies [33], which reported the fatty acid oxidation-promoting effect of choline in the liver of both guinea pigs and humans. These alterations might reduce triglyceride accumulation in the liver and improve liver function, as indicated by decreased serum AST and ALT concentrations in the present study in response to choline supplementation in IUGR pigs.

As the circulating FFA level and hepatic expression of FAS mRNA were increased by IUGR, more PC was needed to package and export triacylglycerol in VLDL to avoid the accumulation of lipid in the liver. PC is synthesized in the liver through two pathways [34]: i) the cytidine diphosphate (CDP) -choline pathway with dietary choline as the substrate; and ii) the methylation of phosphatidylethanolamine catalyzed by PEMT. When the dietary choline was adequate to synthesize abundant PC, PEMT expression and activity are compensatorily down-regulated [35], which was confirmed in IUGR pigs in the current study. The choline supplementation down-regulated the gene expression of PEMT in the liver of IUGR pigs, suggesting stimulating of the CDP-choline pathway to synthesize PC in the IUGR pigs. However, the expression of PEMT mRNA was not altered by choline administration to NBW pigs. These inconsistencies might be attributed to a difference in choline metabolism between IUGR and NBW pigs, as a different choline metabolism status has been observed in people with a different metabolic status [36]. Because IUGR caused a decrease in the circulating level of choline in pigs after weaning [10], we speculate that the high concentration of choline in the supplemented diet helped IUGR pigs to maintain normal circulating levels of choline and adequate PC synthesis.

Sterol regulatory element-binding proteins 1c (SREBP-1c) is one of the most important transcription factors in the liver for regulating de novo fatty acid synthesis through transcriptionally-mediated activation by insulin. The mitochondrial, peroxisomal, and microsomal fatty acid oxidation systems are regulated by peroxisome proliferator-activated receptor alpha in the liver. However, in the present study, transcription factors were not significantly altered by IUGR or choline supplementation. Although the increased expression of fatsynthesizing enzymes might be induced by serum triglycerides [37], the increased expression of FAS in this study was independent of the typical inducers (i.e., circulating insulin and glucose, data not presented) and the mediator SREBP-1c, suggesting that liver lipid metabolism in IUGR offspring may result from metabolic programming [38]. Although it has been suggested that dietary choline intake is an important modifier of the epigenome [39], the effects of long-term supplementation of high levels of choline on metabolic programming and DNA methylation remain to be explored.

In summary, this study demonstrated that finishing pigs with IUGR had abnormal circulating lipid parameters compared with NBW pigs, and that diets with high levels of choline might have a role in regulating hepatic lipid metabolism through decreasing activity of NADPH-generating enzymes and altering expressions of lipid metabolism-related genes. Our data 
provide evidence that treating IUGR offspring after birth with dietary supplementation that includes high levels of choline improves lipid metabolism in the liver. Further research is needed to determine the levels of choline and its metabolites in the liver and in the circulation of IUGR pigs in large groups.

\section{CONFLICT OF INTEREST}

We certify that there is no conflict of interest with any financial organization regarding the material discussed in the manuscript.

\section{ACKNOWLEDGMENTS}

This research was sponsored by the National Natural Science Foundation of China (31272454) and the Research Fund for Postgraduate Innovation Project of Jiangsu Province (CXZZ12_0295). We thank Y. Jiang for her assistance with the real time-PCR experiment. We also express our thanks to T. Kou and B. Chen for their assistance with pig husbandry.

\section{REFERENCES}

1. Wang T, Huo YJ, Shi F, Xu RJ, Hutz RJ. Effects of intrauterine growth retardation on development of the gastrointestinal tract in neonatal pigs. Biol Neonate 2005;88:66-72.

2. Che L, Xuan Y, Hu L, et al. Effect of postnatal nutrition restriction on the oxidative status of neonates with intrauterine growth restriction in a pig model. Neonatology 2015;107:93-9.

3. Li W, Zhong X, Zhang L, Wang Y, Wang T. Heat shock protein 70 expression is increased in the liver of neonatal intrauterine growth retardation piglets. Asian-Australas J Anim Sci 2012; 25:1096-101.

4. Liu C, Lin G, Wang X, et al. Intrauterine growth restriction alters the hepatic proteome in fetal pigs. J Nutr Biochem 2013; 24:954-9.

5. Marchesini G, Bugianesi E, Forlani G, et al. Nonalcoholic fatty liver, steatohepatitis, and the metabolic syndrome. Hepatology 2003;37:917-23.

6. Valsamakis G, Kanaka-gantenbein C, Malamitsi-puchner A, Mastorakos G. Causes of intrauterine growth restriction and the postnatal development of the metabolic syndrome. Ann NY Acad Sci 2006;1092:138-47.

7. Thamotharan M, Shin BC, Suddirikku DT, et al. Glut4 expression and subcellular localization in the intrauterine growthrestricted adult rat female offspring. Am J Physiol Endocrinol Metab 2005;288:E935-47.

8. Siljander-Rasi $\mathrm{H}$, Peuranen S, Tiihonen K, et al. Effect of equimolar dietary betaine and choline addition on performance, carcass quality and physiological parameters of pigs. Anim Sci 2003;76:55-62.

9. Sidransky H, Farber E. Liver choline oxidase activity in man and in several species of animals. Arch Biochem Biophys 1960; 87:129-33.

10. He Q, Ren P, Kong X, et al. Intrauterine growth restriction alters the metabonome of the serum and jejunum in piglets. Mol BioSyst 2011;7:2147-55.

11. NRC. Nutrient requirements of poultry: National Research Council. Washington, DC, USA: National Academy Press; 1998.

12. Engel RW. Modified methods for the chemical and biological determination of choline. J Biol Chem 1942;144:701-10.

13. Noma A, Okabe H, Kita M. A new colorimetric micro-determination of free fatty acids in serum. Clin Chim Acta 1973;43: $317-20$.

14. Reitman S, Frankel S. A colorimetric method for the determination of serum glutamic oxalacetic and glutamic pyruvic transaminases. Am J Clin Pathol 1957;28:56-63.

15. Sullivan DR, Kruijswijk Z, West CE, Kohlmeier M, Katan MB. Determination of serum triglycerides by an accurate enzymatic method not affected by free glycerol. Clin Chem 1985;31: 1227-8.

16. Glock GE, McLean P. Further studies on the properties and assay of glucose 6-phosphate dehydrogenase and 6-phosphogluconate dehydrogenase of rat liver. Biochem J 1953;55:400-8.

17. Huang Q, Xu Z, Han X, Li W. Effect of dietary betaine supplementation on lipogenic enzyme activities and fatty acid synthase mrna expression in finishing pigs. Anim Feed Sci Technol 2008;140:365-75.

18. Xi G, Xu Z, Wu SH, Chen S. Effect of chromium picolinate on growth performance, carcass characteristics, serum metabolites and metabolism of lipid in pigs. Asian-Australas J Anim Sci 2001;14:258-62.

19. MacDonald MJ. Differences between mouse and rat pancreatic islets: Succinate responsiveness, malic enzyme, and anaplerosis. Am J Physiol Endocrin Metabol 2002;283:E302-10.

20. Livak KJ, Schmittgen TD. Analysis of relative gene expression data using real-time quantitative $\mathrm{pcr}$ and the $2^{-\Delta \Delta \mathrm{CT}}$ method. Methods 2001;25:402-8.

21. Ueland PM. Choline and betaine in health and disease. J Inherit Metab Dis 2011;34:3-15.

22. Rehfeldt C, Lefaucheur L, Block J, et al. Limited and excess protein intake of pregnant gilts differently affects body composition and cellularity of skeletal muscle and subcutaneous adipose tissue of newborn and weanling piglets. Eur J Nutr 2012;51:151-65.

23. Attig L, Djiane J, Gertler A, et al. Study of hypothalamic leptin receptor expression in low-birth-weight piglets and effects of leptin supplementation on neonatal growth and development. Am J Physiol Endocrinol Metab 2008;295:E1117-25.

24. Claris O, Beltrand J, Levy-Marchal C. Consequences of intrauterine growth and early neonatal catch-up growth. Semin Perinatol 2010;34:207-10.

25. Taverne F, Richard C, Couture P, Lamarche B. Abdominal 
obesity, insulin resistance, metabolic syndrome and cholesterol homeostasis. PharmaNutrition 2013;1:130-6.

26. Detopoulou P, Panagiotakos DB, Antonopoulou S, Pitsavos C, Stefanadis C. Dietary choline and betaine intakes in relation to concentrations of inflammatory markers in healthy adults: The attica study. Am J Clin Nutr 2008;87:424-30.

27. Dalmeijer G, Olthof M, Verhoef P, Bots M, Van der Schouw Y. Prospective study on dietary intakes of folate, betaine, and choline and cardiovascular disease risk in women. Eur J Clin Nutr 2008;62:386-94.

28. Shirakawa T, Nakajima K, Yatsuzuka S, et al. The role of circulating lipoprotein lipase and adiponectin on the particle size of remnant lipoproteins in patients with diabetes mellitus and metabolic syndrome. Clin Chim Acta 2015;440:123-32.

29. Niu Y, Li S, Na L, et al. Mangiferin decreases plasma free fatty acids through promoting its catabolism in liver by activation of ampk. PLoS One 2012;7:e30782.

30. Turpin S, Hoy A, Brown R, et al. Adipose triacylglycerol lipase is a major regulator of hepatic lipid metabolism but not insulin sensitivity in mice. Diabetologia 2011;54:146-56.

31. Reid BN, Ables GP, Otlivanchik OA, et al. Hepatic overexpression of hormone-sensitive lipase and adipose triglyceride lipase promotes fatty acid oxidation, stimulates direct release of free fatty acids, and ameliorates steatosis. J Biol Chem 2008;283: 13087-99.

32. Lane RH, Kelley DE, Gruetzmacher EM, Devaskar SU. Utero- placental insufficiency alters hepatic fatty acid-metabolizing enzymes in juvenile and adult rats. Am J Physiol Regul Integr Comp Physiol 2001;280:R183-90.

33. Sachan DS, Hongu N. Increases in $\mathrm{vo}_{2} \max$ and metabolic markers of fat oxidation by caffeine, carnitine, and choline supplementation in rats. J Nutr Biochem 2000;11:521-6.

34. Zeisel SH, Da Costa KA, Franklin PD, et al. Choline, an essential nutrient for humans. FASEB J 1991;5:2093-8.

35. Raubenheimer PJ, Nyirenda MJ, Walker BR. A choline-deficient diet exacerbates fatty liver but attenuates insulin resistance and glucose intolerance in mice fed a high-fat diet. Diabetes 2006;55:2015-20.

36. Yan J, Winter L, Burns-Whitmore B, Vermeylen F, Caudill M. Plasma choline metabolites associate with metabolic stress among young overweight men in a genotype-specific manner. Nutr Diabetes 2012;2:e49.

37. Maloney CA, Gosby AK, Phuyal JL, et al. Site-specific changes in the expression of fat-partitioning genes in weanling rats exposed to a low-protein diet in utero. Obes Res 2003;11:461-8.

38. Garg M, Thamotharan M, Dai Y, et al. Glucose intolerance and lipid metabolic adaptations in response to intrauterine and postnatal calorie restriction in male adult rats. Endocrinology 2013;154:102-13.

39. Koletzko B, Shamir R. Prenatal and postnatal nutrition: impact on child health. Curr Opin Clin Nutr Metab Care 2013;16: 290-1. 